BULLETIN Bulletin hispanique

HISPANIQUE Université Michel de Montaigne Bordeaux

114-2 | 2012

Varia

\title{
Itinerario de un sistema de puntuación
}

Fidel Sebastián Mediavilla

\section{OpenEdition}

Journals

Édition électronique

URL : https://journals.openedition.org/bulletinhispanique/2272

DOI : 10.4000/bulletinhispanique.2272

ISSN : 1775-3821

\section{Éditeur}

Presses universitaires de Bordeaux

\section{Édition imprimée}

Date de publication : 31 décembre 2012

Pagination : 937-961

ISBN : 978-2-86781-855-4

ISSN : 0007-4640

Référence électronique

Fidel Sebastián Mediavilla, «Itinerario de un sistema de puntuación », Bulletin hispanique [En ligne], 114-2 | 2012, mis en ligne le 05 janvier 2016, consulté le 28 juillet 2022. URL : http://

journals.openedition.org/bulletinhispanique/2272 ; DOI : https://doi.org/10.4000/bulletinhispanique. 2272 


\title{
Itinerario de un sistema de puntuación
}

\author{
Fidel Sebastián Mediavilla \\ Universitat Autònoma de Barcelona
}

Positurae seu puncta, quasi quaedam uiae sunt sensuum et lumina dictionum.

Casiodoro

Ce travail a pour but offrir une vision panoramique non pas du développement des doctrines mais de l'origine, de l'évolution et du destin divers des différents signes de ponctuation utilisés depuis les origines de l'écriture jusqu'à nos jours.

Mots clés : orthographe, ponctuation, histoire de la ponctuation, systèmes de ponctuation, signes de ponctuation.

El presente trabajo intenta mostrar una visión global no tanto del desarrollo de las doctrinas, cuanto del origen, transformación y varia fortuna de los diversos signos de puntuación utilizados desde los orígenes de la escritura hasta nuestros días.

Palabras clave: ortografía, puntuación, historia de la puntuación, sistemas de puntuación, signos de puntuación.

The present work aims at showing, not as much a global vision of the development of the doctrines, as the origin, transformation and different fortunes of the diverse punctuation signs in use, from the origins of writing until today.

Key words: orthography, punctuation marks, history of the punctuation marks, punctuation marks systems, punctuation marks signs.

$\mathrm{E}$ xiste un interés creciente entre los gramáticos, historiadores de la literatura, críticos textuales y editores de textos por la puntuación; también entre el público culto no directamente implicado en el estudio del lenguaje. Interesa penetrarse bien de los principios por los que se rige una puntuación eficaz 
hoy, conocer los criterios que la regían en épocas pretéritas; interesa conocer el proceso de evolución de unos sistemas y unas señales que se han ido estableciendo y evolucionando a lo largo de los siglos.

En los últimos veinte años han aparecido tratados globales tan importantes como Pause and effect de M. B. Parkes (1993) $)^{1}$ en formato monumental; La ponctuation de Nina Catach $(1994)^{2}$ en modesta edición de bolsillo muy difundida; $y$, más recientemente, una ambiciosa obra colectiva publicada en Italia, Storia de la punteggiatura in Europa $(2008)^{3}$, cuyo apartado dedicado a España ha sido excelentemente desarrollado por mi distinguido colega y amigo Manuel Carrera Díaz 4 . De modo parcial se habían ocupado antes don José Manuel Blecua de la puntuación medieval en «Notas sobre la puntuación española hasta el Renacimiento» (1984) ${ }^{5}$, Ramón Santiago de la puntuación durante la época áurea en "Apuntes para la historia de la puntuación en los siglos XVI y XVII» (1998) ${ }^{6}$, y Jesús Luque Moreno de las raíces antiguas en Puntos y comas $(2006)^{7}$. Yo mismo me he ocupado de las doctrinas atinentes a la puntuación en los gramáticos y en los autores de ortografías anteriores a 1700 en mi tesis doctoral, La puntuación en el Siglo de Oro: teoría y práctica $(2001)^{8}$ y más tarde en La puntuación en los siglos XVI y XVII (2002) ${ }^{9}$ y Puntuación, humanismo e imprenta en el Siglo de Oro (2007) ${ }^{10}$. Finalmente, la Ortografía de la Real Academia y la Asociación de Academias de la Lengua Española $(2010)^{11}$ ha presentado, en su Capítulo III, un auténtico y minucioso tratado de puntuación que ha tenido, naturalmente, en cuenta la investigación precedente.

El propósito del presente trabajo consiste en mostrar una visión global, no tanto del desarrollo de las doctrinas, cuanto del origen, transformación y varia fortuna de los diversos signos de puntuación utilizados desde los orígenes de la escritura hasta nuestros días.

1. M. B. Parkes, Pause and effect (an introduction to the history of puntuation). Berkeley and Los Angeles, University of California Press, 1993.

2. Nina Catach, La ponctuation (Histoire et système). Paris, Presses Universitaires, 1994. Citaremos por la 2a edición corregida, 1996.

3. Storia della punteggiatura in Europa, a cura di Bice Mortara Garavelli. Roma-Bari, Laterza, 2008 .

4. Manuel Carrera Díaz, «La punteggiatura nelle lingue iberiche», ibid., pp. 297-338.

5. José Manuel Blecua, «Notas sobre la puntuación española hasta el Renacimiento», Homenaje a Julián Marias. Madrid, Espasa Calpe, 1984.

6. Ramón Santiago, "Apuntes para la historia de la puntuación en los siglos XVI y XvII», en José Manuel Blecua, Juan Gutiérrez y Lidia Sala (eds.): Estudios de grafemática en el dominio hispánico. Salamanca, Ediciones Universidad de Salamanca, pp. 243-280.

7. Jesús Luque Moreno, Puntos y comas: la grafía de la articulación del habla. Granada, Universidad, 2006.

8. Barcelona, Universitat Autònoma, http://www.tdcat.cbuc.es/TDCat-0720101-093447/.

9. Bellaterra, Servei de Publicacions de la Universitat Autònoma de Barcelona.

10. Sebastián Mediavilla, Fidel, Puntuación, humanismo e imprenta en el Siglo de Oro. Vigo, Academia del Hispanismo, 2007.

11. Madrid, Espasa. 


\section{I. - ANTIGÜEDAD GRIEGA Y LATINA}

La historia de la puntuación en Occidente consiste en una tradición ininterrumpida que comienza hace veintidós siglos, si nos remontamos al mundo latino, y veintiocho, al menos, si tenemos en cuenta los precedentes griegos. Los comienzos de la escritura, en cuanto transcripción visual del habla sobre soporte físico, consistió en una escritura seguida, la scriptio continua, sin separación entre palabras ni otras unidades superiores pertenecientes al texto. Sin embargo, enseguida se echó en falta alguna convención que facilitara una más pronta y eficaz identificación entre lo escrito y aquello que lo escrito pretendía transmitir. Por esta razón, los primeros indicios de señales de división dentro del texto son muy antiguos: Rudolf Pfeiffer recoge el testimonio de un grafito de hacia 700 a. C., encontrado en Ischia, como la inscripción más antigua conocida con signos de puntuación en un texto griego ${ }^{12}$; en cuanto a papiros, los más antiguos provistos de algún signo de puntuación datan de la segunda mitad del siglo IV a. C. ${ }^{13}$. Cicerón apunta que esas señales- posituraeson «aparentemente conocidas entre los griegos desde hace unos cuatrocientos años; entre los latinos desde hace poco» ${ }^{14}$. Su uso, no obstante, no se extendería más que muy lentamente, y con el paso de los siglos. En el II d. C., Aulio Gelio desarrolla en La noches áticas el siguiente diálogo y consideración en torno a la lectura de un texto en scriptura continua:

- Léeme mejor -dijo- lo que no entiendes, para que te lo explique.

- ¿Cómo -le respondí- voy a leer lo que no entiendo? Lo que lea estará mal separado y confuso, y te impedirá a ti también entenderlo.

En ese momento, como algunos de los presentes asentían a lo que yo decía e insistían en ello, tomó el libro que yo le tendía, un antiguo ejemplar de gran exactitud y magníficamente escrito. Lo tomó y se le mudó el rostro de apuro. No me creerán, pero, si unos nińos recién llegados a la escuela hubieran tomado este libro, su lectura no habría sido más ridícula: cortaba las frases en cualquier lugar y pronunciaba las palabras al revés ${ }^{15}$.

Quizás es el momento adecuado de precisar que la puntuación nació como respuesta a una necesidad, no del escritor, sino del lector y del orador:

La puntuación nació para marcar las pausas, los pequeños silencios tan significativos, y nació, como tantas otras cosas, en la antigüedad clásica, cuando la lectura se realizaba en voz alta, y por eso sus relaciones con la retórica son tan claras. El orador y el lector deben respetar las pausas, distinguere, y por esta razón se marcaron con signos los lugares donde se han de hacer esas pausas o distinctiones ${ }^{16}$.

12. Cf. Rudolf Pfeiffer, Historia de la filología clásica. Madrid, Gredos, 1981, vol. I, p. 323.

13. Cf. ibid., pp. 323-324.

14. "Graecos quidem iam anni prope quadringenti sunt, cum hoc probatur; nos nuper agnovimus». M. Tullius Cicero, Orator, 171, ed. P. Reis. Stuttgard, Teubner, 1963, p. 65.

15. A. Gellii Noctium atticarum libri XX, libro XIII, xxxi, 5-20, apud Elena Llamas Pombo, De arte punctandi: Antología de textos antiguos, medievales y renacentistas. Salamanca, Publicaciones del Seminario de Estudios Medievales y Renacentistas, 1999, p. 15.

16. José Manuel Blecua, op. cit., p. 121. 
De los griegos tomaron los latinos los principales valores por los que se regiría la puntuación; pero es preciso tener en cuenta que a lo largo de la Edad Antigua, la Edad Media, e incluso durante el Siglo de Oro, los mismos términos estarían cargados de polisemia, y las funciones que se les adjudicarían serían también cambiantes. Además, una ha venido siendo la teoría, y otra la práctica que han seguido incluso los propios redactores de normas de puntuación.

Durante la época clásica y buena parte de la Edad Media, tres posiciones del punto-alta ["], media [.] y baja [.] - representaban puntuación mayor, intermedia o menor. Quintiliano, que sería el autor más citado durante centurias por los gramáticos, recoge una tradición anterior -invocando en concreto a Cicerón ${ }^{17}$ para señalar que la frase compleja se compone de tres partes: "incisos", que

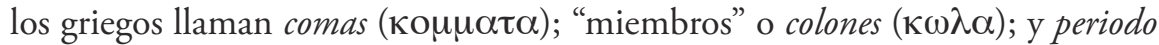
( $\pi \varepsilon \rho\llcorner o \delta o s)$, que es lo mismo que "círculo", "rodeo" o "continuación" o "conclusión"18. Y, para que el lector lo entienda mejor, precisa:

El "inciso", en mi opinión, será definido como la expresión de un pensamiento encerrado en una unidad métrica incompleta, pero la mayoría de los autores lo consideran parte de un "miembro". Así en el ejemplo propuesto por Cicerón (Orat., 223): ¿Te faltaba casa? La tenías. ¿Te sobraba dinero? Lo necesitabas. Una sola palabra también puede constituir un inciso, como: Dijimos, queremos poner testigos. La palabra dijimos es un inciso.

Un "miembro", por su parte, es la expresión de un pensamiento rítmicamente completo, pero separado del cuerpo de la frase, y que no significa nada por sí mismo. ¡O hombres astutos!, es perfecto, pero, separado de los demás, no tiene ningún valor, como la mano, el pie y la cabeza separados del cuerpo [...]. ¿Cuándo, pues, se puede hablar de un cuerpo? Cuando llega el último remate, a saber: ¿A quién de nosotros, por favor, se le escapó que así ibais a hacer vosotros? ${ }^{\text {19 }}$

El inciso, pues, forma parte del miembro, y este se contiene dentro del periodo. Atendiendo a los nombres griegos de cada una de estas unidades (coma, colon y periodo), se advierte enseguida que la confusión va a ser frecuente a la hora de referirse a los signos que separan unidades o a las unidades mismas. No tenía que ser así pues, mientras Quintiliano habla de las partes de la oración (formae), los gramáticos inmediatos se referirán a las distinctiones o positurae, como señales que han de indicar los límites de las partes de la oración y, a la vez, el lugar donde se debe hacer pausa cuando se lee. Así, Diomedes (c. 350), en su tratado «De posituris»:

Conviene atender en la lectura a las positurae o distintiones, que los griegos llaman $\theta \varepsilon \sigma \varepsilon ı s$, las cuales, mientras se lee, proporcionan ocasión de recuperar el aliento, sin cortar el sentido. Estas son tres: distinctio, subdistinctio y media distinctio o mora [...]. Su diversidad se señala con tres puntos colocados en distinta posición: en alto, cuando

17. Cf. Orator, 204-211, ed. citada, pp. 78.

18. «At illa conexa series tris habet formas: incisa, quae commata dicuntur, membra quae $\kappa \omega \lambda \alpha, \pi \varepsilon \rho\llcorner o \delta$ v quae est uel ambitus circumductum vel continuatio vel conclusion». M. Fabio Quintiliano, Institutio oratoria, IX, iv, 22, ed. Ludwig Radermacher. Leipzig, Teubner, 1971, p. 201.

19. Ibid., IX, iv, 122-123 (la traducción es nuestra). 
se acaba el sentido y se llama final entre nosotros (los griegos lo llaman $\tau \varepsilon \lambda \varepsilon \iota \alpha$ ); en medio cuando se da tiempo para respirar al que lee, y se llama medio, los griegos $\mu \varepsilon \sigma \eta$; debajo, cuando, interrumpido el tenor de la frase, de nuevo se interrumpe, y se llama

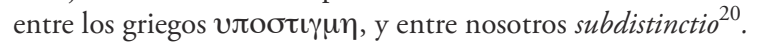

El texto continúa precisando más acerca de cada una de estas unidades y sus puntos, aduciendo ejemplos.

Donato, contemporáneo de Diomedes, será también punto de referencia para todo el medioevo, y para el momento en que se quiera emprender la reforma de la puntuación (en España, a partir de Nebrija). Compuso él también un tratado «de posituris», que recoge en un mismo pasaje la denominación diferenciada de las partes de la sentencia y de los signos que han de separarlas:

Tres son solamente las positurae o distinctiones, que los griegos llaman $\theta \varepsilon \sigma \varepsilon$ ss: distinctio, subdistinctio, media distinctio. Distinctio es cuando termina totalmente la sentencia: este punto lo colocamos por encima de la última letra. Subdistinctio es cuando no falta mucho de la sentencia, pero es necesario marcar una cierta separación: este punto se coloca a la altura de la base de la letra. Media distinctio es cuando casi falta tanto de la sentencia como lo que ya se ha dicho, y es preciso respirar: el punto se coloca entonces a la altura media de la letra. En la lectura, la sentencia completa se llama periodo, y sus partes son los cola y los commata [esto es membra y caesa] ${ }^{21}$.

Innumerables commenta y explanationes al Ars Donati se produjeron durante mucho tiempo, dejando larga estela de sus preceptos, que se verán actuar a su tiempo en los impresores ilustrados del Siglo de Oro.

En resumen, y con nombres más o menos cambiantes, el sistema de puntuación antiguo -iniciado por los griegos y recibido por los latinos- se resume en la concepción de que la "sentencia" se expresa completamente como unidad de significado y de entonación en el "periodo", el cual incluye dentro de sí unidades menores, que se llaman "miembros", y otras menores dentro de estas, que se llaman "incisos". Las señales que distinguen unas unidades de otras son: la distinctio, al final del periodo (consistente en un punto por encima de la línea), la media distinctio al final del miembro (un punto a nivel medio de la última letra), y la subdistinctio, que indica el inciso (un punto al nivel más bajo de la línea).

\section{II. - EDAD MEDIA}

\section{II.1 Nuevas necesidades de la lectura y la escritura}

En un principio la puntuación se había ido desarrollando al ritmo de las necesidades más del lector que del escritor. Por ejemplo, en las escuelas los alumnos puntuaban los textos que habían de leer más tarde en voz alta; por

20. Diomedes, «De posituris», Ars Grammaticae, en H. Keil, Grammatici latini. Leipzig, Teubner, 1857, vol. I, pp. 437-439 (la traducción es nuestra).

21. Donato, «De posituris», Ars Grammaticae, ibid., vol. IV, p. 372 (la traducción es nuestra). 
su parte, el orador preparaba adecuadamente el texto que había de leer, de manera que le trajera a la memoria el modo de hacerlo correctamente cuando se encontrara delante del público: a esta tarea - praelectio - van ligados los orígenes de la puntuación.

La Edad Media recibió y custodió el legado de la antigüedad clásica, y adoptó nuevos medios ante necesidades nuevas que se presentaban en las actividades relacionadas con la lectura y la escritura. La base teórica iba a ser la misma, usando ora una denominación, ora otra sinónima. José Manuel Blecua, en su fecundo estudio acerca de la puntuación en la Edad Media, resumía de este modo la herencia recibida de los antiguos:

La puntuación medieval en toda Europa arranca de los gramáticos de los siglos IV-VII, Donato, Sergio, Diomedes, Casiodoro, san Isidoro, etc., que recogen el sistema clásico, cuya puntuación procuraba indicar la pausa y a veces hasta la inflexión de la voz. Lo mismo Donato que Diomedes o san Isidoro explican las tres positurae vel distinctiones obligatorias [...]. El mismo Sergio ya indica que estas positurae, que más tarde se llamaron pausationes y punctaturae se representaban con un signo único, el punto, que variaba de posición de acuerdo con las positurae que debía indicar. En bajo, señalaba la subdistinctio y se llamaba comma; en medio, indicaba la media distinctio y se llamaba colon; en alto, reflejaba la distinctio y se denominaba periodos. Estos signos duraron mucho más de lo que pueda pensar el lector, puesto que se encuentran aún en más de un incunable ${ }^{22}$.

Sin embargo, sobre la base del punto, se desarrolló a lo largo del medioevo una diversidad de sistemas, y de signos de los que da cumplida cuenta Parkes en Pause and effect.

Focos importantes de vitalidad para el desarrollo de la puntuación surgieron a propósito de la traducción y difusión de la Sagrada Escritura, del desarrollo escolástico, de la liturgia, y de la oración común en el coro de monasterios y conventos. Los copistas de la Sagrada Escritura sintieron una responsabilidad muy particular, puesto que una puntuación defectuosa podía ser causa de alguna herejía. La actividad escolar, por su parte, ponía de nuevo a los discípulos en la necesidad de marcar sus textos con signos para poder leer en voz alta con corrección. La dignidad de la liturgia, sobre todo, y el rezo en coro de los religiosos, requerían una lectura acompasada por parte de toda la comunidad. Finalmente, el trabajo de cancillería de las importantes ciudades y estados, propició, junto con la adopción de un tipo de letra cómodo y claro, el esmero por clarificar el sentido de los escritos; de ahí el interés que se despertó en secretarios y amanuenses por los signos y normas de puntuación.

\section{II.2 Puntuación y Sagrada Escritura}

La preocupación de san Jerónimo (347-420) por la distinctio textus cuando traducía la Biblia al latín le llevó a introducir una modalidad de distribución de la escritura: en lugar de componerla per capitula, es decir, en líneas seguidas

22. Op. cit., pp. 121-122. 
hasta completar cada capitulum, se trataba de hacerlo per cola et commata -miembros e incisos-, de modo que cada línea coincidiera con una unidad sintáctica. Con esta distribución, el primer libro de la Biblia comienza así:

\author{
In principio creavit Deus caelum et terram \\ terra autem erat inanis et vacua et tenebrae super faciem abyssi et \\ spiritus Dei ferebatur super aquas \\ dixitque Deus fiat lux et facta est lux \\ et vidit Deus lucem quod esset bona \\ et divisit lucem ac tenebras \\ appellavitque lucem diem et tenebras noctem \\ factumque est vespere et mane dies unus (Gen. 1, 1-5) $)^{23}$.
}

La tarea del lector quedaba simplificada de esta manera, al saber de antemano que el texto estaba distribuido por miembros que terminaban con la línea ${ }^{24}$. La escritura per cola et commata se difundió mucho gracias al prestigio de san Jerónimo, de modo que se realizaron por toda Europa copias de la Biblia según este procedimiento desde el siglo $\mathrm{v}$ al $\mathrm{Ix}^{25}$.

También san Agustín (354-430) expresó por escrito la importancia de la buena puntuación para la traditio más segura de la Sagrada Escritura: «Cuando las palabras por sí mismas hacen ambigua la Escritura, se ha de ver, en primer lugar, si hemos puntuado mal, o si hemos leído mal» ${ }^{26}$.

Los criterios, y hasta los nombres relativos a la puntuación que expresamente menciona san Agustín, son los que quedaron definidos desde los gramáticos de la Antigua Grecia. Por ejemplo, refiriéndose a un texto de san Pablo (Rom. 5, 3-5):

Se observa aquí un acierto: una vez terminadas algunas de las distintas partes de la frase, por medio de una pausa en la pronunciación (lo que en latín llamamos membra ("miembros") y caesa ("incisos") y en griego se llaman cola y commata), sigue el ambitus o circuitus ("cláusula") que los griegos llaman periodos, cuyos miembros son suspendidos mediante la pronunciación del lector, hasta que se llega al final de dicho periodo ${ }^{27}$.

\title{
II.3 La puntuación en la formación monástica: liturgia y coro
}

Casiodoro, hacia 550, creó en Italia una escuela para formar a sus monjes; dentro de la formación que consideraba más adecuada, incluía una preparación

23. "Librum Genesis ex interpretatione Sacti Hieronymi», Biblia Sacra. Romae, Typis Polyglotis Vaticanis, 1926.

24. Véase, por ejemplo, esta exhortación perteneciente al Praefatio in Ezechielem: «Legite igitur et hunc iuxta translationem nostram, quia per cola scriptus et commata, manifestiorem sensum legentibus tribuit». «Prologus Hiezechielis Prophetae», Biblia Sacra, ed. cit., 1978, vol. XV, p. 6.

25. Cf. Parkes, Pause and effect, p. 15.

26. "Sed cum uerba propria faciunt ambiguam scripturam, primo uidendum est, ne male distinxerimus aut pronuntiauimus» Opera, Pars IV, I, De Doctrina Christiana, libro III, 2, CChr. SL, vol. XXXII, ed. Ioseph Martin. Turnholt, Brepols, 1962, pp. 77-78.

27. Ibid., libro IV, 11, p. 123 (la traducción es nuestra). 
que hiciera de ellos buenos escribas, correctores y eventuales comentaristas. En sus estudios ocupa un lugar destacado la puntuación: las positurae (los signos) y las distinctiones (el lugar de los signos). «Los signos de puntuación, dice, son como caminos del significado y luminarias de las palabras, tan instructivos para los lectores como el más claro de los comentarios $\aleph^{28}$. Frente a la escritura per cola et commata de san Jerónimo, Casiodoro prefiere el sistema de Donato, y los demás autores clásicos.

San Benito, por su parte, había fundado Montecasino en 525, y sentado un modelo que seguiría infinidad de monjes de unas y otras órdenes y congregaciones religiosas. En los monasterios benedictinos, una vez se dio por terminada la labor de copia y corrección de los textos sagrados, se centró la atención en lo principal de la consagración de sus monjes: el cultivo de la vida espiritual. La lectura meditada que lleva a cabo el benedictino en su celda no hace tan precisa la puntuación, como la lectura en voz alta propia de la liturgia o del coro. Es por esta razón por lo que los monjes del siglo vi no suelen indicar los puntos dentro de la sentencia -solo marcan los finales-, con el fin de permitir que sea el lector quien descubra el verdadero sentido del texto.

En el siglo siguiente, nuevos tiempos hicieron ver, en la Iglesia, la importancia de la palabra escrita como medio para transmitir su mensaje a otras generaciones. Mientras que para san Agustín las palabras escritas eran signos de los sonidos -que sirven para recordarlos-, para san Isidoro las palabras son signos de las cosas, que se pueden leer silenciosamente, en ausencia del autor. Estamos en el siglo viI, y san Isidoro de Sevilla aumenta el número de signos de puntuación, añadiendo a los de pausa, o positurae, las notas sententiarum, que son el origen de las anotaciones críticas. En lo que se refiere a las positurae refrenda la tríada clásica de colum, comma y periodos, y da por válida la versatilidad de los términos, que se pueden utilizar para designar tanto a los signos, como a las unidades sintácticas que estos signos delimitan:

Los signos de puntuación sirven para delimitar las partes de la frase en cola, commata y periodos $\mathrm{y}$, si se emplean conforme a su gradación, nos muestran el sentido del texto escrito [...]. El primer signo de puntuación se llama subdistinctio y también comma. El segundo es la media distinctio o cola. Y el último signo es la distinctio, que cierra toda la sentencia, y se llama también periodo [...]. Al inicio de la proposición, cuando esta no es aún una unidad de sentido completa y, sin embargo, se necesita respirar, encontramos un comma, esto es, una pequeña división de la frase; este tipo de punto se coloca al lado de la última letra, en la parte inferior, y por tal razón se llama subdistinctio. Cuando, a continuación, la frase va tomando sentido, pero aún falta algo para la plenitud de dicho sentido, encontramos el colon, que escribimos con un punto a la altura media de la letra, razón por la cual lo llamamos distinctio media. Cuando llegamos ya a una frase con pleno sentido en la pronunciación de nuestro discurso, encontramos un periodo y ponemos un punto junto a la parte superior de la letra, al que llamamos distinctio, esto es disiunctio (“distinción”, “separación”), porque separa una frase completa ${ }^{29}$.

28. «Istae siquidem positurae seu puncta, quasi quaedam uiae sunt sensuum et lumina dictionum, quae sic lectores dociles faciunt tamquam si clarissimis expositoribus imbuantum. Casiodoro, De institutione divinarum litterarum, cap. xv, Migne PL, LXX, cols. 1129 D-1130 A.

29. Isidori Hispalensis Episcopi, Etymologiarum sive originum libri XX, libro I, De grammatica, 
Véase todavía otro texto de san Isidoro que ayuda a esclarecer los conceptos, por manidos, muchas veces expresados con falta de precisión:

La oración se compone de palabras y se estructura en comma, colon y periodo. Comma es una parte pequeña de la oración; colon es un miembro de esta. Periodo es la frase completa y terminada. El comma se forma por la trabazón de palabras; el colon por la unión de commata y el periodo por el enlace de cola. Un comma es el límite de un enlace de palabras; por ejemplo (Cic. Mil. 1): Etsi vereor, iudices: esto es un comma y después sigue otro comma: ne turpe sit pro fortissimo viro dicere, lo cual forma ya un colon, es decir un miembro, puesto que es una parte de frase que ya aporta un sentido; pero aún permanece incompleta la oración, hasta que, después de varios miembros, llegamos al periodo, es decir, a la cláusula última de la oración: ita veterem iudiciorum morem requirunt. El periodo no debe ser más largo de lo que permite una sola expiración ${ }^{30}$.

Liga, por tanto, los aspectos estructurales y semánticos con los retóricos, que serán las tres líneas por las que se regirá con más o menos equilibrio, con mayor o menor acierto, la intención de los gramáticos y escritores que, a lo largo de los siglos, quieran atender a este aspecto de la escritura y la elocución.

El influjo de san Isidoro de Sevilla estuvo muy presente en el ánimo de los gramáticos medievales posteriores. La referencia a sus escritos será autoridad suficiente para sustentar unos presupuestos que san Isidoro había recibido de los clásicos y había prestigiado con su propio crédito personal. Su influencia se prolongó principalmente hasta el siglo IX.

\section{II.4 - Siglos IX a XII: nuevos sistemas y símbolos}

Un nuevo paso adelante supuso la actividad cultural que se desarrolló en torno a la Corte de Carlomagno. Allí se llevó a cabo una labor de copia como nunca antes se había efectuado en ningún centro de cultura o de influencia política. En sus scriptoria se aplicaron las primitivas formas de puntuación con continuas variaciones; en general, abandonaron la media distinctio, para pasar a un sistema binario compuesto de distinctio y subdistinctio.

A partir de la segunda mitad del siglo Ix se introdujo un nuevo sistema de símbolos (o positurae): punctus versus (consistente en un punto con una vírgula curva debajo; parecido al punto y coma [;], pero por debajo de la línea de escritura) para cerrar la cláusula que contiene una aseveración; punctus interrogativus (un punto con un rasguillo sinuoso ascendente hacia la derecha que recuerda al actual punto de interrogación [?]) para cerrar la cláusula que contiene una pregunta; $y$ punctus elevatus (con la forma de un punto con una especie de coma superpuesta [.']) para cerrar una unidad de sentido, pero que no contiene toda la sentencia. Posteriormente se añadió el punctus flexus (con la forma de una $u$ coronando el punto) para indicar una pausa menor que la

cap. xx, «De posituris», 1-5, ed. W. M Lindsay. Oxford, Typographea Clarendoniana, 1956 (la traducción es nuestra).

30. Ibid., libro II, De Rethorica et Dialectica, cap. xviii, «De colo, commate et periodis», 1-2, apud Elena Llamas Pombo, op. cit., p. 65. 
mediana que señalaba el punctus elevatus. En concreto, el punto interrogativo se extendió rápidamente desde la corte de Carlomagno a las otras cortes.

Por otra parte, las positurae empezaron a usarse en libros no litúrgicos, que se usaban fuera de los templos: por ejemplo, la regla del monasterio, que era leída a los monjes en voz alta durante las comidas en el refectorio. El sistema clásico de las distinctiones presentaba un inconveniente, que es la dudosa interpretación de la altura que ocupa cada punto, para su correcta interpretación. Por esta razón, las nuevas positurae que reforzaban los puntos con algún otro trazo fueron adoptadas por los monjes del Císter y los cartujos, y utilizadas hasta el siglo XIV o XV. El punctus flexus se dejó de usar, y en cambio, el punctus elevatus y el interrogativus han permanecido hasta hoy como colon o dos puntos [:] y signo de interrogación [?].

En el siglo XII, según Parkes ${ }^{31}$, las fundamentales convenciones del medio escrito estaban establecidas. Los escribas, sin embargo, al encontrarse con ejemplares puntuados con sistemas diferentes - con varios a la vez, si diversos lectores habían ańadido sus propios signos- fueron relajando sus criterios. Se puede decir que el repertorio general de la puntuación en la Baja Edad Media tiene unos componentes comunes: en primer lugar, el uso del punto, con muy diversas funciones; en segundo lugar, el punto como base para la formación de los otros signos, como el punctus elevatus, y el punctus interrogativus. Con la incorporación de estas positurae y el empleo de las litterae notabiliores [mayúsculas] que resaltan el comienzo de la frase, la altura de los puntos dejó de tener importancia, con lo que poco a poco el sistema primitivo se fue extinguiendo.

\section{II.5 - Siglo XIII: las universidades y los textos eruditos}

El repertorio general de puntuación fue modificándose con el tiempo e incrementándose con nuevos signos para solventar nuevas necesidades. A partir del siglo XIII, la aparición de las universidades exigía otros tipos de textos, que habían de ser estudiados y mencionados a su vez en otros escritos, y se recurrió de nuevo a la tradición grecolatina, que en la época alejandrina (siglos III-II a. C.)

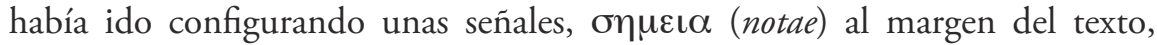

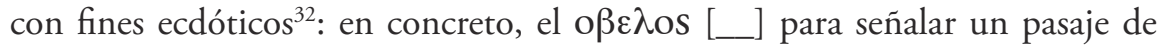
dudosa autenticidad; el $\delta \iota \pi \lambda \eta[<]$ como llamada al margen, o al pie de página; el $\alpha \sigma \tau \varepsilon \rho \iota \sigma \kappa o s ~\left[{ }^{*}\right]$ para seńalar versos que estaban cambiados de orden; y

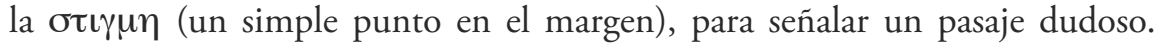
Finalmente, también introdujeron la separación de los libros de que se componía un volumen mediante una línea en blanco y un $\pi \alpha \rho \alpha \beta$ o $\lambda$ os de cierre [ 7 ] y, al comienzo de la siguiente unidad, un $\pi \alpha \rho \alpha \beta \gamma \lambda$ os de abertura que siguió una

31. Cf. op. cit., pp. 41-42.

32. Acerca de los semeia griegos, se pueden consultar las obras citadas de Pfeiffer, vol. I, pp. 213, ss; Catach, pp. 16-17, y Parkes, pp. 57 ss. 
evolución progresiva [desde $\Gamma$ hasta $\$$ ]. En los escritos medievales, a partir del siglo XIII, se empezó a usar mucho el calderón [ $\mathbb{\mathbb { I }}$ ], ordinariamente coloreado: el escriba señalaba con una doble barra oblicua [//] el lugar donde el rubricator había de insertarlo. Su forma se estilizó en la que hoy se utiliza en imprenta [ $\mathbf{g}$ ]. Este signo proviene de una lenta evolución de la C (sigla de "caput") con que se iniciaban los capítulos. A lo largo del siglo XII, para no confundirlo con la C capital, se le añadió una barra vertical, quedando con esta forma $[\mathbb{\mathbb { L }}]$. A partir de aquí, la "nota" fue transformándose por obra de los "rubricatores". La forma más evolucionada se ve por primera vez en manuscritos de finales del XII y se extendió a todo tipo de textos durante el XIII. En ambas figuras $[\mathbb{I}]$ y $\mathbf{g}]$ lo veremos iniciando capítulos en los libros impresos del XV, y menos en el XVI, hasta desaparecer en el XVII.

Este calderón fue haciéndose poco a poco con las funciones del antiguo paragraphus, llegando a servir para separar cualquier unidad más o menos extensa del texto: capítulos, párrafos, sentencias, y también para numerar las signaturas de los folios preliminares en los libros impresos (privilegio, tasa, fe de erratas, etc.), que se imprimían después de censurado y aprobado el texto propiamente dicho.

En los siglos XVI y XVII, los comienzos de capítulo pasaron a ser señalados de modo universal por una letra inicial especialmente grande $y$, a ser posible, muy adornada, la letra "capital", aunque no dejarán de verse calderones, esporádicamente, en textos tardíos.

El viejo paragraphus $[\$]$ se conservó y se conserva, sobre todo, en los escritos de carácter jurídico, para señalar subapartados.

La vírgula suspensiva [/] entró a formar parte del nuevo sistema, coexistiendo con el punto y solapándose con él en la atención a unas funciones poco definidas: a veces se usaban indistintamente en un mismo texto para unos mismos fines. Así llegaría hasta los primeros libros impresos, en el siglo xv. En impresos más tardíos, entrado el XVI, se advierte una especie de convención admitida poco a poco por los impresores según la cual se asignaba a los dos signos (punto y barra) funciones diferentes: la virgula suspensiva se reservaría para marcar las pausas medias, mientras el punto marcaría la pausa final.

Por lo que toca a España, las positurae clásicas tampoco se aplicaron durante la Edad Media con toda rigidez. Los signos empleados en los códices y documentos visigóticos pertenecen a más de un sistema, y su equivalencia respecto a los actuales no se deja precisar. Los más frecuentes son:

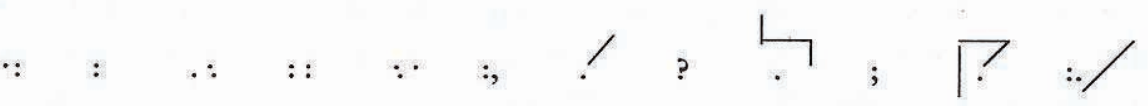

Entre estos signos visigóticos están aquellos que darían forma y función adecuada, llegado su momento, al interrogante, al signo de admiración, y al punto y coma ${ }^{33}$.

33. Cf. Agustín Millares Carlo, Tratado de paleografía española. Madrid, Espasa Calpe, 1983, p. 283. 


\section{II.6 La escritura humanística}

Al final de la Edad Media, primero los dictaministas ${ }^{34}$, y más tarde los humanistas del siglo XV se preocuparon de estimular la escritura de un latín correcto y elegante. Favorecieron la epístola como vehículo de comunicación: el descubrimiento de las cartas de Cicerón había producido un profundo efecto en ellos. Empezaron a escribir sus propias cartas, vertiendo en ellas sus experiencias y opiniones de un modo subjetivo, en primera persona, imitando las obras, las actitudes y los ideales de los clásicos. El principal ideal literario de los humanistas era la eloquentia. Puesto que miraban la elocuencia como un proceso que llevaba a perfeccionar su propia expresión, cada uno atendía a su personal modo de puntuar, más que a seguir un determinado método o el modelo de un formulario. Petrarca y Boccaccio, por ejemplo, prestaron mucha atención a la puntuación de sus obras. Ambos combinaron elementos de diferentes repertorios: mientras Petrarca empleaba cuatro signos, Boccaccio utilizaba cinco para indicar las pausas dentro del periodo, para seńalar los commata y los cola, y para indicar la naturaleza de las relaciones entre estas unidades de la frase.

Nuevos signos reemplazaron a otros en el desempeño de determinadas funciones. El paréntesis, que se había venido indicando mediante sendas virgulas suspensivas [//] o cola [: :], a partir del siglo XIV se empezó a señalar mediante un nuevo signo con la forma $\Gamma$ que poco después se reemplazaría por un par de corchetes en forma de ángulos agudos: < >; más tarde, los paréntesis acabarían adoptando la forma de dos virgulae convexae: ( ).

El semicolon [;], que hoy llamamos punto y coma, apareció en escena con publicidad a finales del siglo xv, en el círculo humanista que se reunía entorno a Aldo Manuzio el Viejo: en su imprenta veneciana se estamparía por primera vez, en 1494, en el De Aetna de Pietro Bembo. Este nuevo signo tuvo desde el principio toda la apariencia de un compromiso, una deliberada invención destinada a satisfacer una necesidad que explicaría Aldo Manuzio el Joven en su Interpungendi ratio (1561), indicando que se ha de colocar allí donde «si semicirculum apponas parum sit; si gemina puncta nimium $»^{35}$.

El paréntesis y el semicolon reflejan la necesidad de quienes estaban acostumbrados a leer en silencio. Otro signo nuevo, el punctus admirativus o exclamativus [!] refleja más obviamente el ideal oratorio de los humanistas. Iacopo Alpoleio da Urbisaglia declara haberlo inventado:

Ego vero, videns quod exclamativa vel admirativa clausula aliter soleat quam continuus vel interrogativus sermo enunciari, consuevi tales clausulas in fine per punctum planum et coma eidem puncto lateraliter superpositum ${ }^{36}$.

Lo recogió y difundió el florentino Coluccio Salutati (1370-1431), autor de un tratado de ortografía, atribuido en Italia a Petrarca ${ }^{37}$. Estos tres signos -el

34. En Italia, a partir del siglo XII se desarrolló el llamado ars dictaminis, como una disciplina retórica centrada en la redacción de cartas.

35. Cf. Puntuación, humanismo e imprenta en el Siglo de Oro, pp. 37-38 y 102-103.

36. Apud Parkes, Pause and effect, p. 49.

37. Cf. Nina Catach, op. cit., p. 28. 
paréntesis, el semicolon y el signo de admiración- pasaron al repertorio general que quedaría a disposición de un público cada vez más amplio, a través de su utilización en los textos impresos, de insospechada difusión.

La contribución de los humanistas al repertorio de puntuación fue importante por sí misma, pero fue mucho más importante la consideración con que realzaron este aspecto de la escritura. En sus escritos y copias demandaban una mayor distinción entre los elementos que constituyen la sentencia, lo que les llevaba necesariamente a buscar nuevos signos, a renovar el repertorio general. Su ejemplo incidiría directamente en los primeros impresores, $y$, a través de los primeros impresos -que serían tomados por modelo-, en las generaciones siguientes de gramáticos, escritores, correctores, y cajistas.

\section{III. - EDAD MODERNA Y CONTEMPORÁNEA: LA IMPRENTA}

\section{III.1 Incunables y tipos góticos}

Contra lo que se podría pensar, los primeros impresores -y buena parte de sus clientes- sentían un cierto complejo de inferioridad frente a los trabajos realizados por los escribas, encuadernados en códices, obras únicas y, en ocasiones, de una perfección formal muy elevada. Se entiende por ello -y también porque no contaban con otro modelo- que los primeros impresores intentaran reproducir en sus libros, en la medida de lo posible, el aspecto de los códices manuscritos. Entre lo que se imitaba, destaca el tipo de letra, y también el sistema de puntuación. Los más antiguos productos de la imprenta no conocieron más tipos de letra que el "gótico" y el "romano". Dentro de la denominación genérica de "letra gótica» se incluyen tres tipos: el textura ("anguloso"); el "casi humanístico", littera fere humanistica o de suma (con tendencia a redondear sus rasgos), y la littera rotunda, que se diferencia del tipo textura por el predominio de las curvas en algunas letras. Este es el único carácter gótico que emplearon los impresores españoles del siglo xv y de parte de la centuria siguiente ("letra de tortis"). En cuanto al tipo "romano", parece probado que sus creadores fueron los tipógrafos Schweynheim y Pannartz, quienes se sirvieron de él para imprimir en el monasterio de Subiaco un Lactancio, De divinis institionibus, el primer libro estampado en Italia.

Por lo que respecta a la puntuación, muchos incunables ${ }^{38}$ utilizan tres tipos de pausas: punctus [.], virgula [/] e interrogativus [?].

38. De incunabulum, "cuna'. El término lo aplicó por primera vez a una categoría de impresos el librero holandés Cornelio van Beughem en el repertorio que tituló precisamente Incunabula typographiae, sive Catalogus Librorum Scriptorumque proximis ab inventione Typrographiae annis, usque ad Annum Christi M. D. inclusive, Amsterdam, Johannes Wolters, 1688. En España, el primer incunable de que se tiene noticia, las Actas del Sínodo de Aguilafuente (Sinodal), se atribuye a las postrimerías de 1472, y se conserva en la Biblioteca capitular de Segovia (en edición facsímil: Carlos Romero de Lecea, El Sinodal de Aguilafuente, Madrid, Colección de Joyas Bibliográficas, 1965). 


\section{III.2 Siglos XVI y XVII: triunfo de los tipos redondos}

Durante el siglo XvI, la imprenta española, que comenzó usando los tipos góticos tradicionales, los fue sustituyendo por los redondos o venecianos, a imitación de los usados en el taller de Aldo Manuzio y sucesores ${ }^{39}$.

Estos símbolos, que habían desarrollado los humanistas, aparecieron por primera vez en la imprenta con ocasión de la edición de los clásicos que algunos de ellos llevaban a cabo, o de sus propias obras: de este modo entraron en la imprenta el paréntesis semicircular y el semicolon o punto y coma.

Al principio de la imprenta, sus propietarios se encargaban de la fabricación de los tipos: "cortar" el punzón con el signo invertido, grabar con este una matriz o molde, fundir en el molde el metal y vaciarlo. Buscaban su modelo en los tipos más elegantes de los más afamados estampadores. Pero a partir de 1520 aproximadamente se generalizó la compra de los tipos a casas especializadas, con lo que la unificación de las "fuentes" se aceleró a lo largo y ancho de toda Europa.

Algunos tipos ejercieron una influencia muy notable; en concreto, los empleados por la casa de Aldo Manuzzio, confeccionados a partir de los punzones de Francesco Griffo; sus signos de puntuación son los que hoy en día nos resultan más familiares: la coma semicircular, el paréntesis semicircular también, el interrogativo vertical, y, por intervención directa del Bembo, el semicolon. La fama de Aldo Manuzio como impresor le llevó a ser imitado también por cortadores como el francés Claude Garamond, cuyos tipos serían universalmente conocidos. También el prolífico e ilustrado estampador Plantin de Amberes compró las matrices precisas para obtener los mismos tipos. En consecuencia, la letra y los signos góticos acabaron cediendo en favor de los italianos.

Aunque la nueva puntuación estaba al alcance de los impresores, estos no necesariamente la emplearon desde el principio: de hecho, la coma y el paréntesis curvos tardaron en incorporarse a los textos impresos.

El semicolon, especialmente, tardó en ser aceptado por los impresores: lo usaron Aldo Manuzio y otros tipógrafos de Venecia, Roma y Vicenza. En España, el primer gramático que propuso la utilización de este signo fue Felipe Mey en su De orthografhia libellus, vulgari sermone scriptus, ad usum tironum.

39. La historia tipográfica del siglo xvı se inicia en Europa con el nombre del impresor italiano, establecido en Venecia hacia 1490, Aldo Manuzio (el Viejo). Publicó a partir de 1494 alrededor de 130 ediciones, sobre todo de clásicos griegos y latinos, entre las cuales hay 27 principes. Con un Virgilio de 1501 inauguró la serie de sus libros en $8^{\circ}$ (enchiridii forma), en los cuales empleó el elegante tipo de letra cursiva al que nos referimos. Ejemplo de editor humanista, fue huésped durante dos años de Pico de la Mirandola; se rodeó de los sabios de mayor renombre, en especial de helenistas, para elegir los textos que habían de imprimirse. Entre ellos, Bembo y Erasmo. El escudo de Aldo Manuzio - un delfín enroscado en la caña de un ancla- apareció por primera vez en el libro titulado Poetae christiani veteres (1502). También son notables por su belleza los tipos griegos usados por el impresor. Le sucedieron Pablo, y Aldo el Joven, a cuya muerte (1597) se extinguió la dinastía. 
Instruccion para bien escrevir en lengua Latina, y Española (1606), con el nombre de colon imperfecto ${ }^{40}, y$, más tarde lo hizo el originalísimo Gonzalo Correas en su Ortografia kastellana, nueva i perfeta de 1630, donde le aplica el nombre de hupokolon ${ }^{41}$. A partir de aquí, este signo fue ya recogido en los sistemas de gramáticos e impresores.

Probablemente el semicolon tardó tanto en ser aceptado porque sus aplicaciones no eran fáciles de diferenciar de las del punto doble -colon-. Sin embargo, era normalmente usado por escolares y escribas. He podido comprobar, comparando un elenco de originales de imprenta-manuscritos puestos en limpio, corregidos y rubricados, listos para ser copiados por el cajista- con sus correspondientes ediciones impresas, que la insistencia del uso en el manuscrito fue venciendo la resistencia de los impresores, sobre todo cuando estos advertían que el manuscrito había sido puntuado según criterios coherentes $^{42}$.

El apóstrofo ['] -con muy escasa fortuna en España-, se consolidó, en todo caso, como símbolo de omisión. Se utilizó ocasionalmente en nuestro país, por ejemplo en la edición de la obra de Garcilaso, tanto en la princeps (1543), como en la edición del Brocense (1574), y en las Anotaciones de Fernando de Herrera (1580): «Pues en un'ora junto me llevastes / todo'l bien, que por terminos me distes» (Soneto X, vv. 9-10) ${ }^{43}$. Pero no prosperó. Prevaleció el criterio de no introducir una costumbre ajena al castellano como era también ajena al latín, según argumenta Juan López de Velasco en su Ortografía (1582):

En la escriptura Griega, e Italiana, ay otro punto, o señal, que llaman apostropho, y es como el medio punto, o coma, puesto por la parte alta del renglon, donde por auerse juntado dos vocales, vna del fin de vna diccion, y otra del principio de otra se pierde la vna dellas, como D'amor, por de amor, mill'anni, por mille anni, que aunque en la pronunciacion y lengua Castellana, y en el Latin, se pierde muchas vezes la dicha vocal, en la escriptura, no se quíta, ni ay para que introduzirla, pues tampoco lo vemos vsado en el Latin ${ }^{44}$.

La obra de Velasco, en general, influiría poderosamente, con el tiempo, en la conformación de la que sería doctrina ortográfica de la Real Academia ${ }^{45}$.

Precisamente el mismo López de Velasco documentó por primera vez la diéresis como otro signo de puntuación. Hasta entonces el término se utilizaba para referirse a la licencia poética consistente en deshacer un diptongo para obtener una sílaba más en el verso. Pero Velasco, si bien reconoce el nuevo

40. Cf. Puntuación, humanismo e imprenta..., pp. 47-49 y 115-117.

41. Cf. ibid., pp. 53-55 y 126-127.

42. Véase Sebastián Mediavilla, «Del manuscrito al impreso», La puntuación en el Siglo de Oro: teoría y práctica, citada más arriba, pp. 101-143.

43. Obras de Garcilaso de la Vega con anotaciones de Fernando de Herrera, ed. facsimilar. Madrid, CSIC, 1973, p. 122.

44. Juan López de Velasco, Orthographia y pronunciacion castellana, Burgos, 1582, p. 292. Puede leerse en Sebastián Mediavilla, Puntuación, humanismo e imprenta en el Siglo de Oro, p. 107.

45. Cf, ibid., p. 39. 
signo ["], le atribuye una función parcial, para distinguir en caso de duda la grafía $u$ o $i$ con valor de vocal y no de consonante en palabras como Malüenda/ Maluenda [Malvenda] ${ }^{46}$. Felipe Mey en 1606 le atribuye la virtud de indicar la diéresis métrica, por más que -hijo de su tiempo- escoja los ejemplos en lengua latina: «La nota del dieresis que son los dos puntos por largo, se ponen sobre vna de las dos vocales, que como se dixo en los diftongos [sic] hazen vna sillaba, y esta señal declara que son dos como aër, Marïa» ${ }^{47}$. La primera vez que el Diccionario de la Real Academia utilizó el signo de diéresis con valor ortográfico para señalar que se ha de pronunciar la $u$ en los conjuntos güe, güi, fue en su segunda edición, de 1770, en palabras como argüir o agüero.

\section{III.3 El siglo XVIII y la Real Academia Española}

La práctica española de emplear un punto interrogativo invertido al comienzo de la pregunta se desarrolló en la segunda mitad del siglo XviII. En los libros impresos anteriores a esa fecha se siguió la práctica de colocar solamente un punto interrogativo al final de la frase. En sesión del 5 de marzo de 1739, la Real Academia decidió establecer unas reglas generales de ortografía del español, y en 1741 las publicó en forma de tratado en la primera edición de la Ortografía ${ }^{48}$. Como parte de este proyecto, la Academia abordó el problema de la puntuación en las preguntas, y aportó la solución en la segunda edición, publicada en 1754:

La dificultad ha consistido en la elección de nota: pues emplear en esto las que sirven para los acentos y otros usos daria motivo á equivocaciones, y el inventar nueva nota sería reparable y quizas no bien admitido. Por esto despues de un largo exâmen ha parecido á la Academia se pueda usar de la misma nota de interrogacion, poniendola inversa antes de la palabra en que tiene principio el tono interrogante, ademas de la que ha de llevar la cláusula al fin de la forma regular, para evitar así la equivocacion que por falta de alguna nota se padece comunmente en la lectura de los periodos largos... ${ }^{49}$.

El punctus exclamativus o admirativus fue tratado del mismo modo. Una y otra práctica fueron adoptadas en libros publicados bajo los auspicios de la Academia, pero la práctica general no se siguió de inmediato, sino que se fue incorporando lentamente.

Es en el siglo XviII cuando comienzan a utilizarse los puntos suspensivos, primero para seńalar que se omite parte de una cita textual; más tarde para indicar una interrupción o suspensión temporal del discurso. En estos casos se escriben varios puntos seguidos en número no definido, en principio más o

46. Velasco, p. 293 (Cf. Puntuación, humanismo e imprenta..., p. 107).

47. Felipe Mey, Instruccion para bien escrevir. Véase en Puntuación, humanismo e imprenta en el Siglo de Oro, p. 117.

48. Orthographia española /compuesta y ordenada por la Real Academia Española... Madrid, Imprenta de la Real Academia Española, 1741.

49. Ortografía de la lengua castellana / compuesta por la Real Academia Española / Nueva edicion corregida y aumentada. Madrid, Imprenta de D. Gabriel Ramirez, 1754, p. 126. 
menos según la longitud de lo omitido o el tiempo de suspensión que se quiera significar. El número de tres para todos los casos no se consolidaría hasta el siglo XIX: la primera edición de la Ortografía de la Real Academia (1741) escribe siete (......) y los menciona entre los que llama «signos auxiliares».

Otro signo se incorporó a partir del primer tercio del siglo Xvin: la Ortografia de Boldázar ${ }^{50}$ daba autoridad al uso de corchetes [ ] como una variante de los paréntesis para citas textuales más bien largas.

Algunos de los antiguos signos críticos sobrevivieron a través de los siglos y adquirieron nuevos roles en el libro impreso; otros no eran adecuados para ser trasladados a un tipo de metal, por lo que cayeron en desuso. Dos de ellos sobrevivieron como notae: el asterisco [*] y el obelus en forma de cruz $[\dagger]$. El asterisco aparecía ocasionalmente en primitivos manuscritos medievales, pero con menos frecuencia después. En los libros impresos, según su función original, señala omisiones dentro del texto: se colocaba en el margen solamente para indicar una sentencia o una expresión gnómica. El obelus, en cambio, abandonó pronto su función original -señalar lecturas espurias o erróneas-, aunque cruces de una u otra forma aparecen frecuentemente en manuscritos medievales para llamar la atención sobre un texto. Las notas de reenvío para señalar fuentes, al margen o al pie, se señalaban dentro del texto mediante números, y también mediante las letras del abecedario.

Mientras el asterisco y el obelus permanecieron como notae, el diple se fue transformando en un signo de puntuación con significado en sí mismo. En la antigüedad lo insertaban en el margen los lectores para llamar la atención sobre alguna nota importante en el texto. En el siglo xvi se empleó en los textos impresos del mismo modo, como nota en los márgenes. En tipografía, el diple $[>>$ ] se representó por un par de comas semicirculares [,, ,,]; luego las comas se invirtieron [" "]. Las llamadas comillas latinas o españolas [" "] conservan con mayor aproximación la fisonomía del antiguo diple. A finales del XVI, el diple pasó del margen al interior de la línea, y de este modo dejó de ser una anotación para convertirse en un signo de puntuación que indica acotaciones de autoridades, y, por extensión, citas en estilo directo (es raro encontrar su presencia en impresos anteriores al siglo XVII).

\section{III.4 Siglos XIX a XXI: nuevos signos y convenciones gráficas}

Los recursos gráficos para indicar diálogo quizás han sido los más tardíos en llegar a unificarse. De hecho, no se estabilizaron hasta el siglo xIx signos y convenciones particulares: guiones, comillas y espaciados, fundamentalmente.

Hoy en día, la puntuación es uno de los campos de experimentación de ciertos autores vanguardistas. La disponibilidad de signos es amplia. La

50. Antonio Boldázar de Artazú, Ortografia española fijamente ajustada a la naturaleza invariable de cada una de las letras, Valencia, en la imprenta del propio autor, 1728, citado por Manuel Carrera Díaz en "La punteggiatura nelle lingue iberiche», Storia della punteggiatura in Europa, citada arriba, p. 319. 
enseñanza de su uso sigue siendo deficitaria. La conciencia de arbitrariedad que los escritores tienen acerca de las reglas de puntuación es con frecuencia exagerada. Los autores modernos siguen comportándose de formas tan variadas como sus antecesores: unos dejan la puntuación al criterio de la secretaria o del secretario al que dictan o entregan un borrador; otros dan a corregir la puntuación a persona de su confianza; casi todos confían en la correcciones del editor; algunos experimentan con la omisión de toda puntuación, y otros postulan nuevos signos para necesidades que sienten no atendidas, como los seis points d'intonation suplementarios que reclama entre bromas y veras Hervé Bazin: le point d'amour, le point de conviction, le point d'autorité, le point d'ironie, le point d'acclamation y le point de doute ${ }^{51}$. De hecho, estamos asistiendo a la incorporación de novedades que quieren significar y que se hacen entender, como la multiplicación de admiraciones [!!!] o la puesta entre paréntesis de un interrogante al final de una frase [(?)] para expresar perplejidad o ironía.

Felizmente, la Real Academia Española, después de largos años de espera, publicó en 1999 una edición actualizada de su Ortografía ${ }^{52}$, en la que prestaba a la puntuación una consideración muy apreciable, precisando mucho más de lo que lo había hecho con anterioridad, las normas y usos propios de cada uno de los signos de puntuación que hoy se emplean en nuestra lengua. Recientemente, la edición de $2010^{53}$ ha superado en mucho la precisión de las orientaciones para una fructuosa puntuación.

\section{IV. - EVOLUCiÓN Y MUTACIÓN EN LOS NOMBRES DE LOS SIGNOS}

De una parte, como se ha dicho más arriba, desde tiempos tempranos, un mismo nombre se aplicaba a la señal que separaba una parte de la oración y a la misma unidad separada. Más tarde, algunos nombres se intercambiaron para designar uno lo que antes se designaba con otro. Por si fuera poco, por la dificultad de la materia y las deficiencias de las ediciones, frecuentemente no se corresponde la teoría de los ortógrafos con la práctica de sus propios textos, ni condicen los ejemplos que aducen con lo que exponen teóricamente más arriba.

Teniendo en cuenta esta versatilidad, puede ser útil para el lector tener a la vista en un mismo cuadro las distintas denominaciones que dan a los signos básicos de puntuación distintos autores a lo largo de los siglos, comenzando en el siglo I antes de Cristo, y llegando hasta la última edición de la Ortografía de la Real Academia Española, de 2010.

51. Véase Hervé Bazin, Plumons d'oiseau (divertissement). Paris, Bernard Grasset, 1966, pp. 141-143.

52. Madrid, Espasa, 1999.

53. Ortografía de la lenga española. Madrid, Espasa, 2010. 


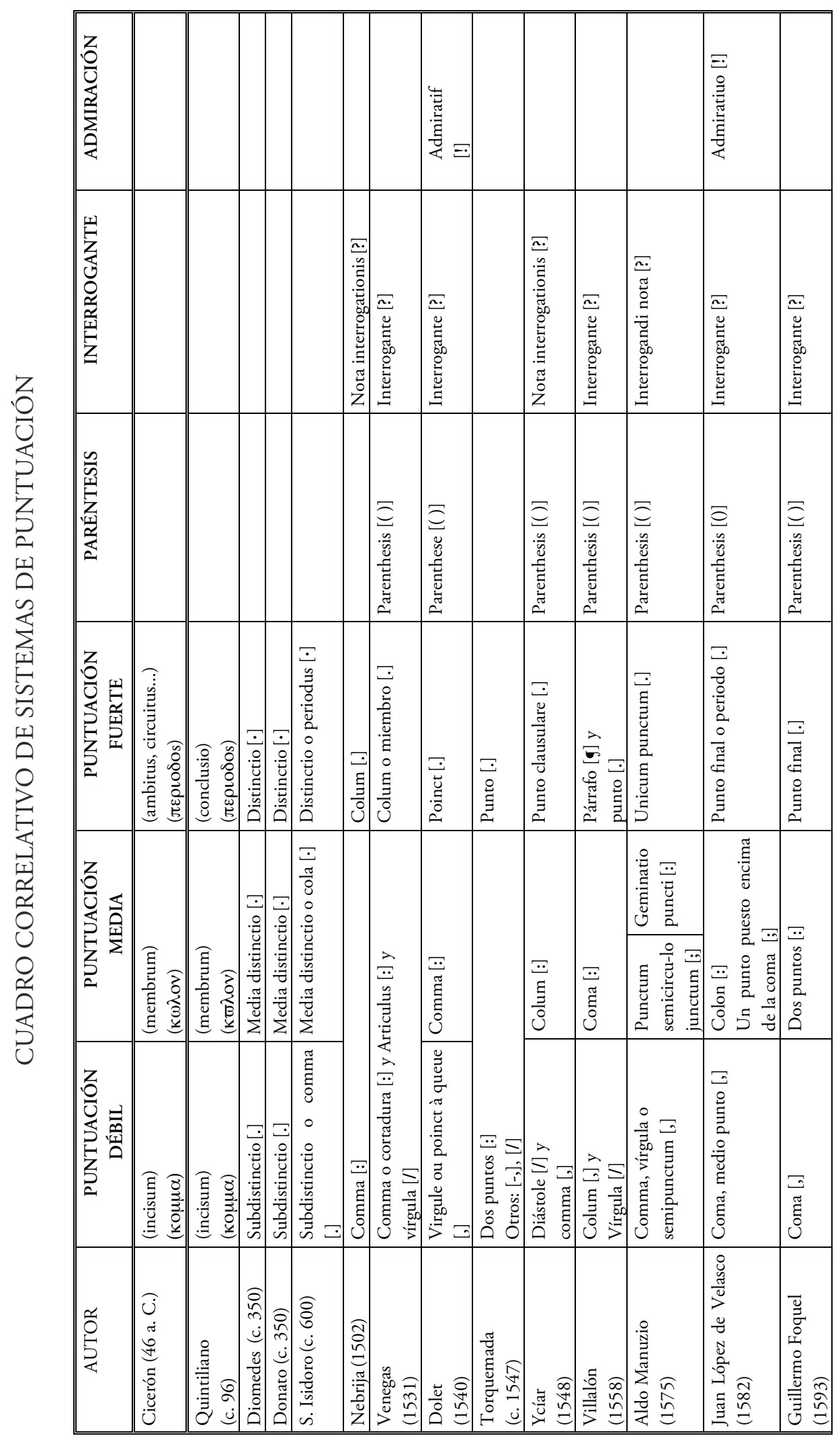




\begin{tabular}{|c|c|c|c|c|c|c|c|c|}
\hline 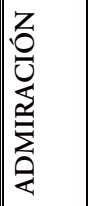 & 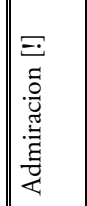 & 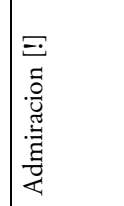 & 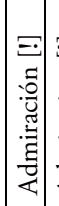 & 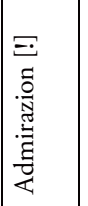 & 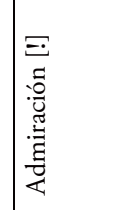 & 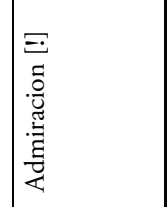 & 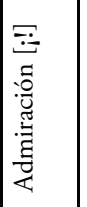 & 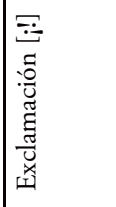 \\
\hline 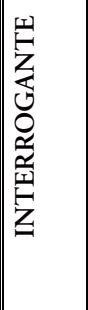 & 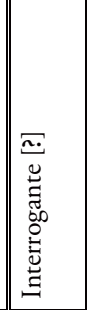 & 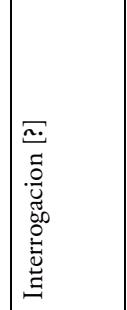 & 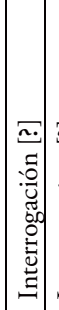 & 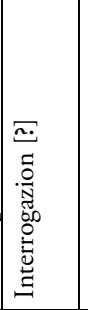 & 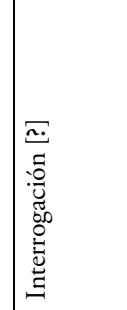 & 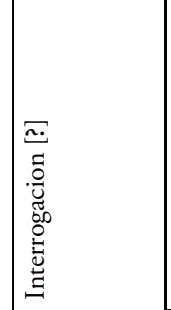 & 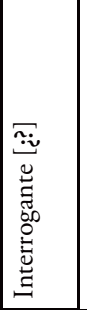 & 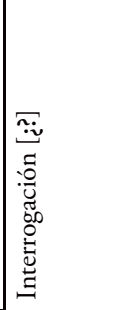 \\
\hline 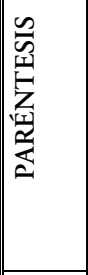 & 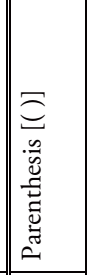 & 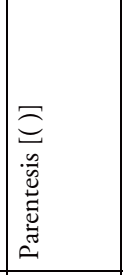 & & 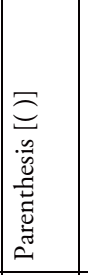 & 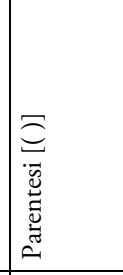 & 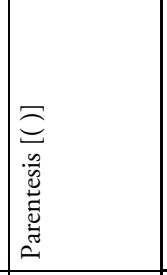 & 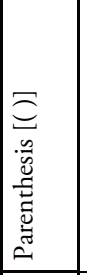 & 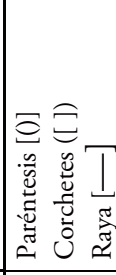 \\
\hline 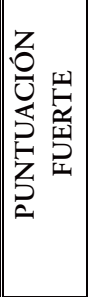 & 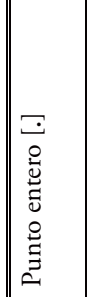 & 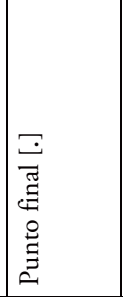 & & 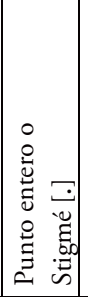 & 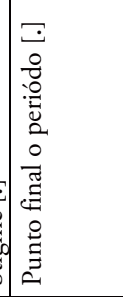 & 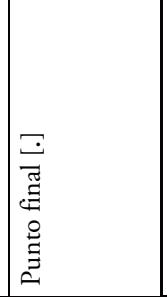 & 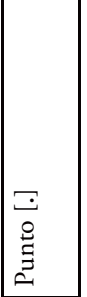 & 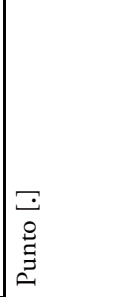 \\
\hline \multirow{2}{*}{ 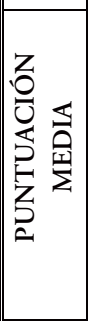 } & \multirow{2}{*}{ 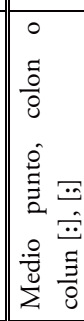 } & 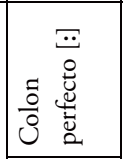 & & 咅 & . & 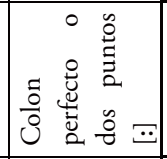 & 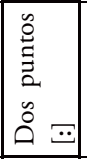 & 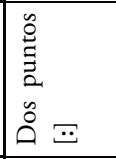 \\
\hline & & 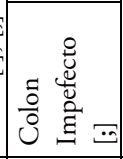 & : & 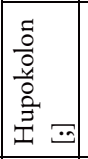 & 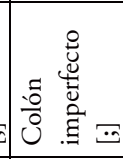 & 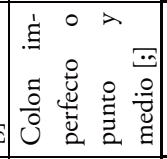 & 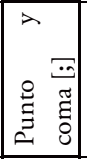 & 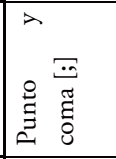 \\
\hline 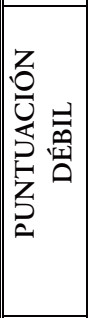 & 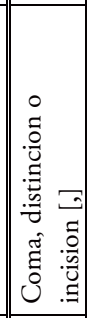 & 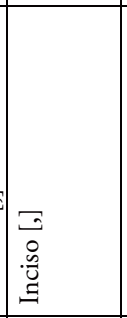 & & 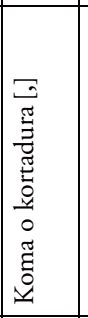 & 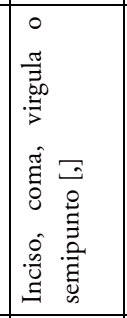 & 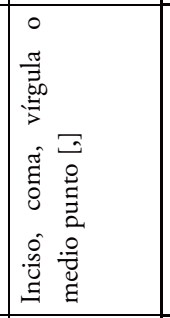 & 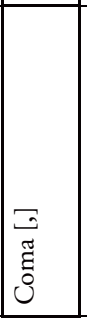 & 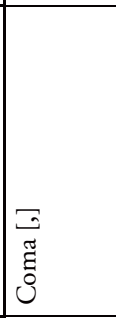 \\
\hline 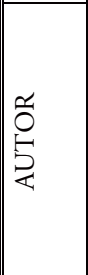 & 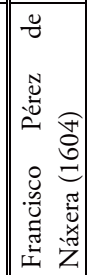 & 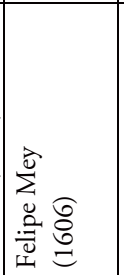 & 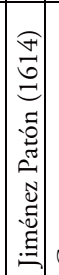 & 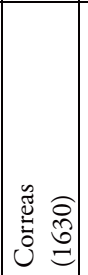 & 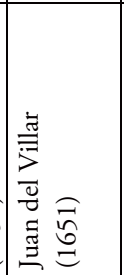 & 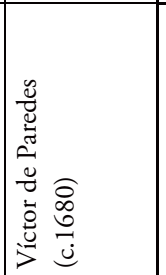 & 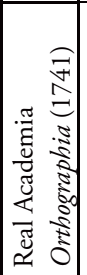 & 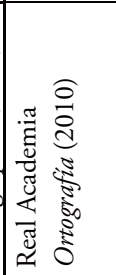 \\
\hline
\end{tabular}




\section{V. - LA PUNTUACión EN LAS ObRAS MAESTRAS DEL SIGLO DE ORO}

Empieza a ser generalmente admitido que la puntuación de los impresos ha venido siendo competencia de la imprenta más que del autor. En concreto, durante nuestros siglos áureos, XVI y XVII, la ortografía y la puntuación del texto que se imprimía corría por cuenta del corrector de imprenta, y en su ejecución intervenían -siguiendo más o menos las indicaciones del corrector- el amanuense que preparaba la "copia en limpio", y los cajistas que irían trasladando al "componedor", tipo tras tipo, el modelo. Consta, excepcionalmente, la intervención personal y muy cuidadosa de unos pocos escritores, como Francisco de Herrera o Mateo Alemán. De Cervantes sabemos que apenas puntuaba sus escritos, y conocemos los manuscritos de santa Teresa prácticamente sin puntuación.

Distintas ediciones de una misma obra presentan diferencias de puntuación, a tenor de la imprenta que las estampa. Las primeras ediciones de algunas de las obras maestras de nuestra literatura salieron puntuadas con los siguientes medios $^{54}$ :

54. Me he ocupado de su estudio por extenso en «La primeras ediciones de La Celestina y su puntuación», Boletín de la Real Academia Española, Tomo 83, Cuaderno 287, 2003, pp. 113135; «Puntuación (y filiación) del Lazarillo», Bulletin Hispanique, Tomo 110, 2008, pp. 61-90; «Mateo Alemán y la puntuación del Guzmán de Alfarache», Lectura y signo, 3, 2008, pp. 237270; La puntuación del Quijote (1605 y 1615), Vigo, Academia del Hispanismo, 2008; Fray Luis y Santa Teresa; imprentas y editores (cuestiones de ortografía y puntuación), Vigo, Academia del Hispanismo, 2010 y «Lope corregido por “los originales del propio autor' (puntuación y ortografía de la Sexta parte)", Anuario Lope de Vega, Tomo XVI, 2010, pp. 181-210. 


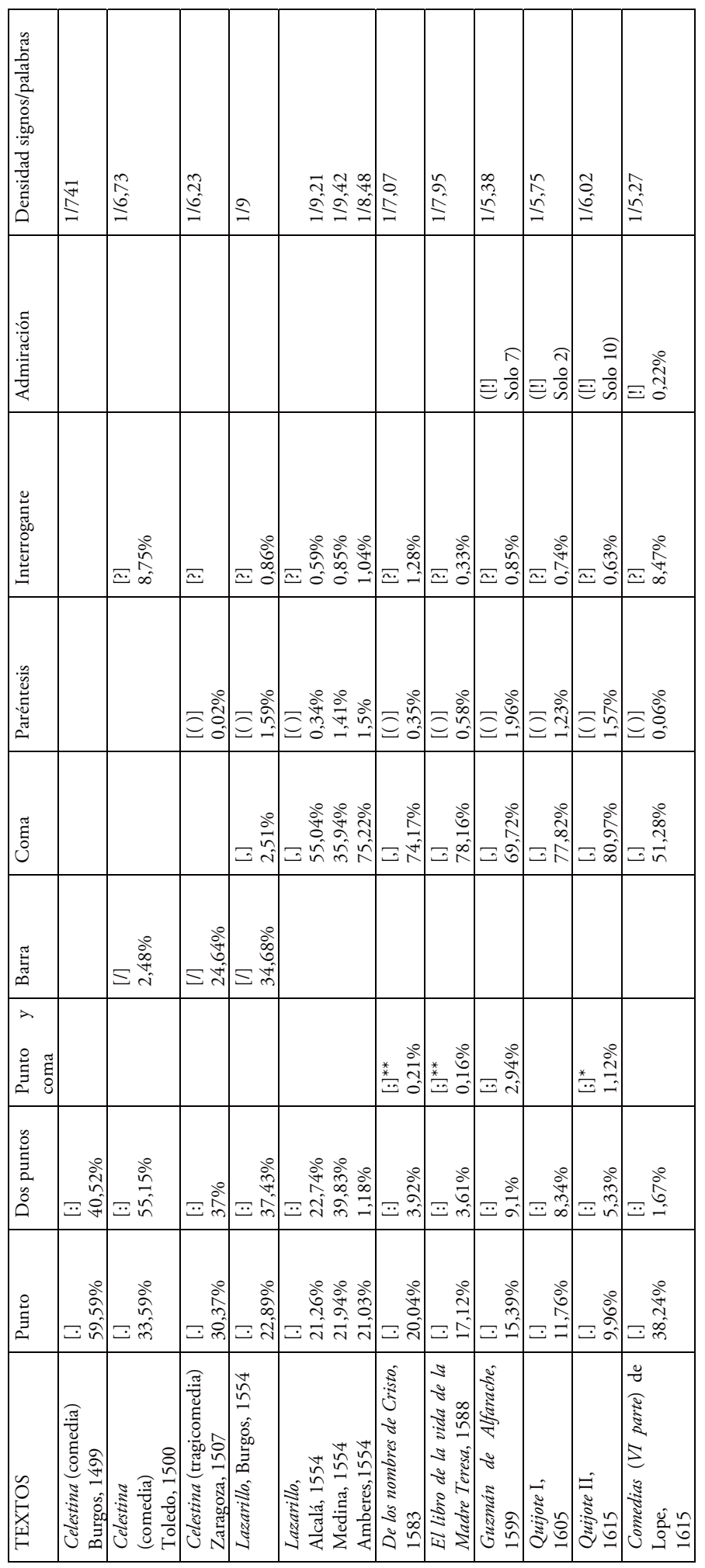


Como se puede apreciar, la edición burgalesa de La Celestina de dieciséis actos salió puntuada tan solo con puntos y dos puntos y sin signos de interrogación. Las otras dos (Toledo, 1500, y Sevilla, 1501) utilizan, además, la barra y, sobre todo, el interrogante, tan necesario en un texto dialogado, máxime si, como $\mathrm{La}$ Celestina, está concebida para la lectura en voz alta.

La barra, que se utiliza -salvo en la de Burgos, 1499- en las ediciones de La Celestina de dieciséis actos (comedia) y algunas de las más antiguas de la tragicomedia de veintiuno, se usará en una sola de las ediciones del Lazarillo de 1554, la de Burgos, para desaparecer del panorama de nuestra letras en favor del la coma curva, que en esa misma edición burgalesa del anónimo comparte funciones con la barra, y la desplazó completamente desde las otras ediciones del mismo año en adelante.

El punto y coma tardó mucho en encontrar un lugar en el sistema de puntuación de nuestras letras. La Primera parte del Quijote (1605) no lo contempla, y en la Segunda (1615) se hace un uso escaso de él. Tras una aparición testimonial del signo en De los nombres de Cristo de fray Luis de León (1583) y en las obras de la Madre Teresa (1588), el punto y coma ocupa un lugar en el sistema ordinario de puntuación que Mateo Alemán -sujeto activo de la ortografía de sus escritos- utilizó en la Primera parte de Guzmán de Alfarache (1599).

Los dos puntos cumplían la misión de separar las partes de la oración y de marcar el punto de inflexión, en el paso de la prótasis a la apódosis. Como un adelantado, Herrera utilizó el punto y coma con estas dos funciones, prescindiendo, en su caso, de los dos puntos por completo.

Finalmente, el signo de admiración tardó mucho, también, en incorporarse de pleno al sistema de puntuación. Los dos aislados admirantes que aparecen por sorpresa en el Libro de la vida de Santa Teresa se pueden considerar intervención de un cajista que actúa por su cuenta y riesgo, contra el sistema establecido para la puntuación de la obra. Los escasos signos de admiración (siete) que se ven en la primera edición del Guzmán (1499) fueron eliminados por el propio autor en las siguientes (las autorizadas de Madrid, 1600 y Sevilla, 1602, y la edición pirata de Madrid 1601, en realidad también revisada por el escritor). En la Primera parte del Quijote el signo de admiración aparece tan solo en dos ocasiones, lo que sirve para mostrar que el tipo estaba en los cajetines, y que si no se usó todas las veces que hubo oportunidad de hacerlo es sencillamente porque el símbolo no se había incorporado todavía a los hábitos puntuadores de algunas imprentas, la de Juan de la Cuesta en particular, que todavía en 1615, al imprimir la Segunda parte del Quijote, estampó tan solo diez veces el signo de admiración. En todas estas obras, como se usaba antes de que existiera el signo apropiado $^{55}$, las oraciones exclamativas se siguieron puntuando sencillamente con un punto o, en todo caso, para indicar un cambio de entonación, con el viejo interrogante.

55. Vid. supra, II. 6. 


\section{Bibiografía}

Augustinus Hipponensis, Opera, Pars IV, I, De Doctrina Christiana. CChr. SL, vol. XXXII, ed. Ioseph Martin. Turnholt, Brepols, 1962.

Bazin Hervé, Plumons l'oiseau (divertissement), Paris, Bernard Grasset, 1966.

Blecua José Manuel, «Notas sobre la puntuación española hasta el Renacimiento». Homenaje a Julián Marías. Madrid, Espasa Calpe, 1984.

Boldázar de Artazú Antonio, Ortografia española fijamente ajustada a la naturaleza invariable de cada una de las letras. Valencia: en la imprenta del propio autor, 1728.

Carrera Díaz Manuel, «La punteggiatura nelle lingue iberiche», Storia della punteggiatura in Europa, a cura di Bice Mortara Garavelli. Roma-Bari, Laterza, 2008, pp. 297338.

Casiodoro, De institutione divinarum litterarum. Migne PL, LXX.

Catach Nina, La ponctuation (Histoire et systhème). Paris, Presses Universitaires, 1994.

Cicero M. Tullius Orator, 171, ed. P. Reis. Stuttgard, Teubner, 1963.

Diomedes, «De posituris», Ars Grammaticae, en H. Keil, Grammatici latini. Leipzig, Teubner, 1857, vol. I.

Donato, «De posituris», en H. Keil, Grammatici latini. Leipzig, Teubner, 185, vol. IV.

Gellius Aulus. A. Gellii Noctium atticarum libri XX, ed. Carolus Hosius. Stuttgart, Teubner, 1967.

Herrera Fernando de, Obras de Garcilaso de la Vega con anotaciones de Fernando de Herrera, ed. facsimilar. Madrid, CSIC, 1973.

Isidorus Hispalensis, Isidori Hispalensis Episcopi, Etymologiarum sive originum libri XX, ed. W.M Lindsay. Oxford, Typographea Clarendoniana, 1956.

Hieronymus, "Librum Genesis ex interpretatione Sacti Hieronymi». Biblia Sacra. Romae, Typis Polyglotis Vaticanis, 1926.

«Prologus Hiezechielis Prophetae». Biblia Sacra. Romae, Typis Polyglotis Vaticanis, 1978, vol. XV.

Llamas Pombo Elena, De arte punctandi: Antología de textos antiguos, medievales y renacentistas. Salamanca, Publicaciones del Seminario de Estudios Medievales y Renacentistas, 1999.

López de Velasco Juan, Orthographia y pronunciacion castellana. Burgos, 1582.

Luque Moreno Jesús, Puntos y comas: la grafía de la articulación del habla. Granada, Universidad, 2006.

Mey Felipe, Philippi Mey de orthographia libellus, vulgari sermone scriptus, ad usum tironum. Instrucción para bien escrevir en lengua Latina, y Española, incluido en Bartolomé Bravo. Thesaurus verborum, ac frasivm, ad orationem latine efficiendam, et locvpletandam. Palma de Mallorca: en casa de Gabriel Guasp, 1607.

Millares Carlo Agustín, Tratado de paleografía española. Madrid, Espasa Calpe, 1983, p. 283. 
Orthographia española compuesta y ordenada por la Real Academia Española. Madrid, Imprenta de la Real Academia Española, 1741.

Ortografía de la lengua castellana compuesta por la Real Academia Española. Nueva edicion corregida y aumentada. Madrid, Imprenta de D. Gabriel Ramirez, 1754.

Ortografía de la Lengua Espalola. Edición revisada por las Academias de la Lengua Española. Madrid, Espasa, 1999.

Ortografía de la Lengua Espalola. Real Academia Española, Asociación de Academias de la Lengua Española. Madrid, Espasa, 2010.

Parkes M. B., Pause and effect (an introduction to the history of puntuation). Berkeley and Los Angeles, University of California Press, 1993.

Pfeiffer Rudolf, Historia de la filología clásica. Madrid: Gredos, 1981.

Quintilianus M. Fabius, Institutio oratoria, IX, iv, 22, ed. Ludwig Radermacher. Leipzig, Teubner, 1971.

Romero de Lecea Carlos (ed.), El Sinodal de Aguilafuente. Madrid, Colección de Joyas Bibliográficas, 1965.

Santiago Ramón, «Apuntes para la historia de la puntuación en los siglos xvi y xvii», en José Manuel Blecua, Juan Gutiérrez y Lidia Sala (eds.): Estudios de grafermática en el dominio hispánico. Salamanca, Ediciones Universidad de Salamanca, pp. 243-280.

Sebastián Mediavilla Fidel, La puntuación en el Siglo de Oro: teoría y práctica [tesis doctoral]. Barcelona, Universidad Autónoma, 2001, http://www.tdcat.cbuc.es/ TDCat-0720101-093447/, pp. 101-143.

- La puntuación en los siglos XVI y XVII. Bellaterra, Servei de Publicacions de la Universitat Autònoma de Barcelona, 2002.

— «La primeras ediciones de La Celestina y su puntuación». Boletín de la Real Academia Española, Tomo 83, Cuaderno 287, 2003, pp. 113-135.

- Puntuación, humanismo e imprenta en el Siglo de Oro. Vigo, Academia del Hispanismo, 2007.

- La puntuación del Quijote (1605 y 1615). Vigo, Academia del Hispanismo, 2008.

— «Mateo Alemán y la puntuación del Guzmán de Alfarache». Lectura y signo, 3, 2008, pp. 237-270.

— «Puntuación (y filiación) del Lazarillo». Bulletin Hispanique, Tomo 110, 1-2008, pp. 61-90.

- Fray Luis y Santa Teresa; imprentas y editores: cuestiones de ortografía y puntuación. Vigo, Academia del Hispanismo, 2010.

— «Lope corregido por "los originales del propio autor" (puntuación y ortografía de la Sexta parte)", Anuario Lope de Vega, Tomo XV, 2010, pp. 181-210.

Mortara Garavelli Bice (ed.), Storia della punteggiatura in Europa. Roma-Bari, Laterza, 2008.

Van Beughem Cornelio, Incunabula typographiae, sive Catalogus Librorum Scriptorumque proximis ab inventione Typrographiae annis, usque ad Annum Christi M. D. inclusive. Amsterdam, Johannes Wolters, 1688. 